ARCHIVO ESPAÑOL DE ARTE, LXXXI, 324

OCTUBRE-DICIEMBRE 2008, pp. 415-428

ISSN: 0004-0428

\title{
VARIA
}

\section{MIGUEL DE PRET (1595-1644), DOCUMENTOS Y UN CUADRO NUEVO}

La afortunada supervivencia de la firma, "M. de pret - me fecit", en el borde delantero del cuadro Bodegón con cesta de higos, cesta de ciruelas, melón y fruta colgando (fig. 1), nos ha permitido añadir un nombre nuevo a la nómina de pintores de bodegones activos en la corte de Madrid durante la primera mitad del siglo XVII ${ }^{1}$.

A pesar de no estar fechado, se pueden observar en el cuadro algunos elementos característicos de los bodegones de principios de siglo, como aquellos en la obra de Juan van der Hamen (1596-1631), Alejandro de Loarte (c.1600-26), el enigmático Maestro del Bodegón de la Colección Stirling-Maxwell, y otros ${ }^{2}$. Entre estos elementos, está la presentación de los objetos a modo de friso y con una disposición en general simétrica, además del uso de motivos que cuelgan de cuerdas. Los objetos presentes en esta composición relativamente densa están iluminados por una fuerte luz directa y al tener un fondo negro ganan en volumen. Los motivos del bodegón están evidentemente pintados con una considerable atención al detalle. Por ejemplo, la pulpa y las pepitas del melón son objeto de una cuidadosa observación; además, el largo tiempo que esta fruta parece haber estado ante el artista provocó que se hundiera bajo su propio peso.

No nos sorprende la presencia de matices propios de Juan van der Hamen, ya que Pret fue contemporáneo flamenco suyo, de Amberes, y también formó parte de la Guardia flamenca de arqueros $^{3}$. Se encontraba en Madrid al menos desde 1641, fecha en que se incorpora a la Guardia flamenca de arqueros ${ }^{4}$. No llevaba mucho tiempo en este cuerpo cuando a principios de septiem-

1 Madrid, Subastas Alcalá, 6 de octubre de 2004, lote 61.

2 Con respecto a la tipología del cuadro de Pret, véase William B. Jordan, Juan van der Hamen y León y la corte de Madrid, Madrid, Palacio Real, 2005, p. 99, fig. 6.22, Cesta de frutas, melón y racimos de uvas colgadas, p. 108, fig. 6.34, Cesta de frutas con aves de caza colgadas.

3 Para la guardia de los arqueros, ver P. Cherry, Arte y naturaleza. El bodegón español en el Siglo de Oro, Madrid, 1999, pp. 147-50; JoRDAN 2005, pp. 45-50 y María VizCAíno VillanUEVA, El pintor en la sociedad madrileña durante el reinado de Felipe IV, Madrid, 2005, pp. 357-60.

${ }^{4}$ Archivo General de Palacio, Sección Histórica, Caja 170, Rol y lista de la Compañía de los Archeros de la Noble Guardia de Corps del Rey Nuestro Señor.. / De los que an entrado desde el año de 1635 y que hoy en día estan sirviendo (1 de junio de 1662), f. 1v, "Miguel de pret natl de Amberes juro de Archero a 7 de 9bre 1641. de edad de 46 años moço de buen talle pelirubio largo de cara". 


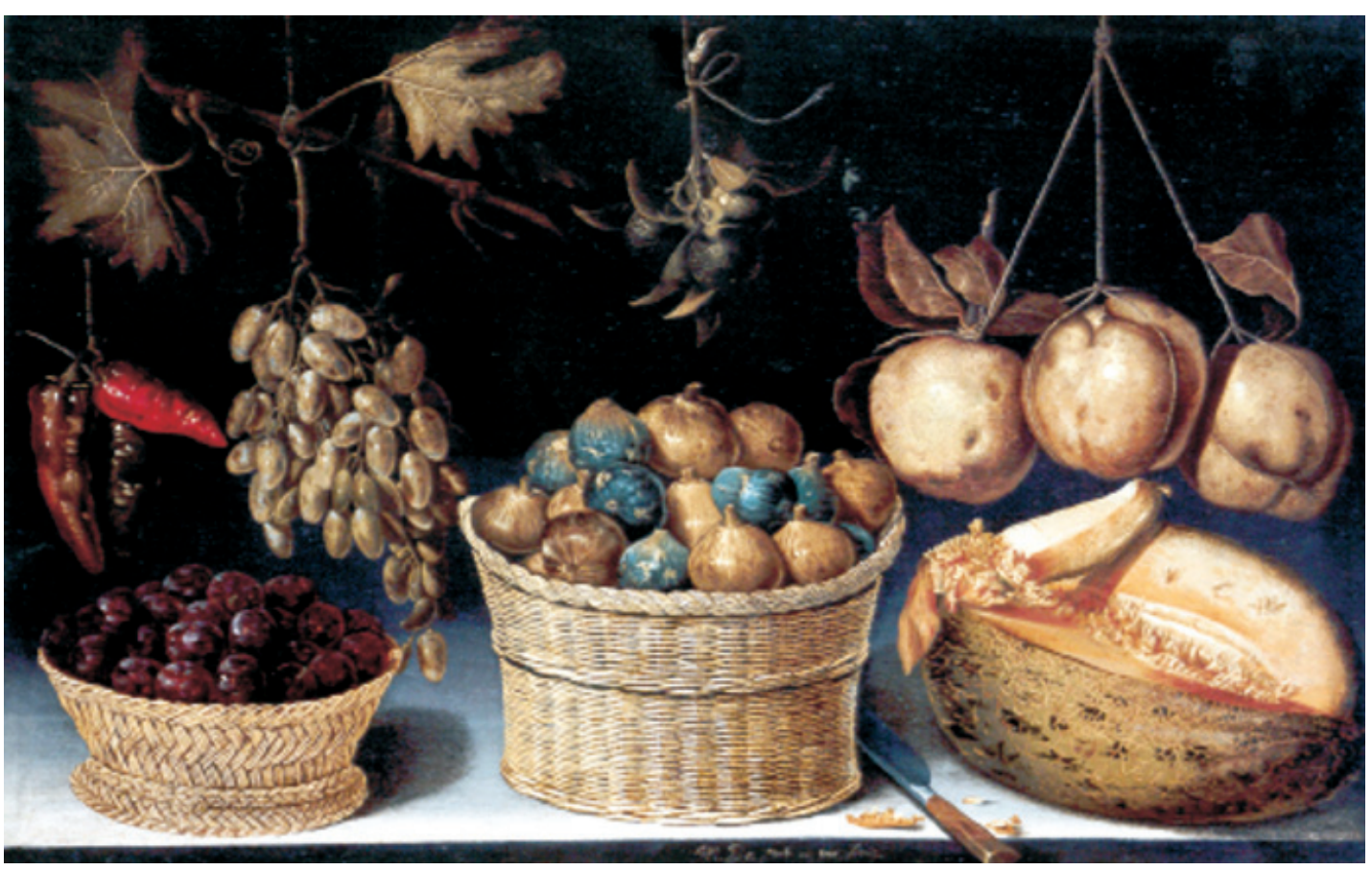

Fig. 1. Bodegón con cesta de higos, cesta de ciruelas, melón y fruta colgando.

Firmado: M. De pret - me fecit. Óleo sobre lienzo, 57,5 ×90 cm. Colección Juan Abelló.

bre de 1644 murió en Zaragoza al servicio del rey. Parece que prestaba sus servicios en la guardia personal real de Felipe IV durante su campaña aragonesa contra la invasión francesa de la región y que fue en la misma jornada en que Velázquez pintó el retrato del monarca que se encuentra ahora en la colección Frick de Nueva York ${ }^{5}$.

La partición de los bienes de Pret en noviembre de 1644, incluye una serie de documentos que arrojan nueva luz sobre su vida y su carrera ${ }^{6}$. Pret contrajo matrimonio con María Cano, su segunda esposa, en $1630^{7}$. En su último testamento, redactado en Zaragoza el dos de septiembre de 1644, nombra albaceas a su mujer y a sus compañeros de la Guardia flamenca de arqueros, Gil de Bey y Bruno de Holfo ${ }^{8}$. En Madrid, el inventario y la tasación de sus bienes fueron realizadas por su viuda y por Daniel de Puente, marido de Manuela Melchora de Pret, hija del pintor y de

${ }_{5}^{5}$ Para esta jornada, véase Carl Justi, Velázquez y su siglo, ed. Madrid, 1999, pp. 415-19; Jonathan Brown, Velázquez. Painter and Courtier, New Haven y Londres, 1986, pp. 169, 173.

${ }^{6}$ Para la partición de los bienes de Pret, que comienza en Madrid el 11 de noviembre de 1644, ver Archivo Histórico de Protocolos de Madrid, Prot. 7674, s.f.

7 Véase AHPM, Prot. 7674, para una copia de la dote de María Cano (de valor de 3132 reales), fechada el 25 de abril de 1630, y el "Aumento de dote" (de valor de 594 1 1/2 reales), a favor de "Miguel de pret pintor flamenco", fechado el 8 de diciembre de 1630 .

8 Véase AHPM, Prot. 7674, para una copia del testamento e última voluntad de Miguel de Pret, "Archero del Rey nuestro señor Don felipe quarto domiciliado en la villa de Madrid Corte de su magestad", otorgado en Zaragoza, el 2 de septiembre de 1644, testamento citado por Matilla TASCón, A., Índice de testamentos y documentos afines, Madrid, AHP, 1984. 
su primera esposa Damiana Abarca ${ }^{9}$. Los cuadros y el taller de Pret fueron tasados por el pintor Juan de la Corte, otro colega de origen flamenco, el 25 de septiembre de $1645^{10}$. Entre ellos, había un pequeño número de cuadros de temática religiosa de un valor relativamente modesto y material del artista $^{11}$.

La gran cantidad de bodegones inventariados, no menos de sesenta y seis, nos llevan pensar que ésta era la principal actividad artística de Pret, y se repartieron entre María Cano y Daniel de la Puente. La mayoría de los cuadros aparecían como bodegones de frutas ("fruteros"), y entre los cuales había un grupo de obras de pequeño tamaño que según el inventario representaban los doce meses del año ${ }^{12}$. Evidentemente, Pret también pintaba flores; hay un grupo de doce "ramilleteros" y otro de seis cuadros descritos como "Ramilleteros I fruteros"13. Los únicos bodegones cuya temática se describe con cierto detalle son un par de cuadros de los que se dice explícitamente que representan "un naranjo y en el otro un limón con sus tiestos", de los cuales el notario evidentemente señaló sólo los motivos más destacados de estas obras relativamente grandes ${ }^{14}$. La firma de Pret en Bodegón con cesta de higos, cesta de ciruelas, melón y fruta colgando demuestra lo orgulloso que se sentía de sus logros como pintor de bodegones y hay constancia de otra obra suya firmada en al menos una colección del Madrid del siglo XVIII ${ }^{15}$. La singular personalidad de Pret en la pintura de bodegones y el volumen de obras de esta naturaleza inventariadas en su taller tras su muerte, nos llevan a afirmar que hay muchos más cuadros suyos esperando ser redescubiertos.

\section{Peter Cherry Trinity College, Dublín}

\footnotetext{
9 AHPM, Prot. 7674, Inventario de los bienes de Miguel de Pret, que comienza en Madrid el 24 de septiembre de 1644. El testamento e inventario del artista están recogidos en la base documental del estudio de VizCAíno ViLLANUEVA, op. cit., p. 455, I 128; p. 464, T 119.

${ }^{10}$ AHPM, Prot. 7674, Tasación de pinturas por Juan de la Corte, pintor, el 25 de septiembre de 1644. El valor global de la hacienda de Pret llegó a 7.057 reales.

${ }^{11}$ Los temas de once de las pinturas de caballete en la tasación comprendieron Cristo, el Ecce Homo, Nuestra Señora de la Leche, San Pedro, San Juan Bautista, San Miguel y Santa Lucía, "un quadro pequeño de media bara de largo en questa pintada la muerte", un retrato de fray Melchor Cano, y dos lienzos de dos búhos. Habían "sesenta y quatro liencos imprimados", piedras de moler colores, tres caballetes de pintar, "unos papeles de dibujo con un Cajon de ancorca" y "un libro del angel de La guarda y otro en que trata de los linajes". Para estos utensilios véase VizCAínO VillanUEVA, op. cit., pp. 78, 104, 123, 136.

12 La tasación cita, como lotes, cuatro "fruteros... de los meses del año", de vara y media, tasados en 40 reales cada uno; treinta y ocho "fruterillos" de media vara, tasados en 20 reales cada uno; seis "fruteros", de vara y cuarta de alto, tasados en seis ducados cada uno.

${ }^{13}$ La tasación cita un lote de doce "ramilleteros" de tres cuartas de vara de alto, tasados en 30 reales cada uno; y un lote de seis "Ramilleteros i fruteros" tasados en ocho ducados cada uno, descritos en el inventario como "fruteros de jarrones" de vara y cuarta.

${ }^{14}$ Lo citado viene de la entrada del inventario; en la tasación, los cuadros aparecen descritos como "dos lienços de un naranjo y otro de un limon" con un valor de 176 reales y, a sus dos varas, son los bodegones más grandes del documento.

15 Bonaventura Bassegoda, "La colección pictórica del canónigo don Pablo Recio y Tello (Yunquera de Henares 1765-Madrid 1815)", Locus Amoenus, 8 (2005-06), pp. 233-64, p. 259, n. ${ }^{\circ} 381$, "Un frutero con un membrillo, una pera partida y un racimo de ubas. Original de Miguel de Piet [sic]. Tiene de alto un pie y una pulgada por once pulgadas de ancho $[30,1 \times 25,5 \mathrm{~cm}]$; en sesenta reales", p. 259, n. $^{\circ} 382$, "Otro frutero compañero del anterior pero del mismo autor, aunque [no] está firmado. Es de igual tamaño; en sesenta reales.".
} 